\title{
Retos del Instituto Nacional Electoral en la designación de los consejeros electorales de los organismos públicos locales electorales
}

\section{Adriana Favela Herrera*}

\section{Sumario:}

I. Introducción

II. El nombramiento de los consejeros electorales locales como facultad exclusiva del Instituto Nacional Electoral

III. Importancia de los aspectos subjetivos en la designación de los consejeros electorales locales

IV. Procedimiento de elección de los consejeros de los organismos públicos locales electorales

V. Los retos del Instituto Nacional Electoral en la designación de los consejeros electorales locales

VI. Consideraciones finales

VII. Bibliografía

* Consejera electoral en el Instituto Nacional Electoral. 


\section{Introducción}

Motivo de señalamiento y crítica por su aparente parcialidad, se ha sostenido que los institutos electorales de las entidades federativas acusan la intromisión de los gobernadores y las dirigencias partidistas locales, tanto en su integración como en la toma de decisiones. El argumento principal se fundamenta en que los órganos electorales perdieron credibilidad y son estructuras dependientes de los gobiernos locales, a quienes sirven con entreguismo olvidando su carácter de árbitros imparciales. Se suma al cuestionamiento la expresión relativa al enorme costo que pudiera significar la operación de 32 institutos electorales locales.

Dado que la designación de los consejeros electorales estatales era avalada por los congresos locales, nacidos de un partido hegemónico, se afirma que desde el inicio se viciaba su voluntad. Por ser elegidos a través del partido en el poder, los consejeros toman decisiones que se apartan del principio de imparcialidad que debiera regir su actuación. Frente a tal escenario, en el proyecto inicial de una reforma político electoral, misma que llegó a ser considerada la puerta por la que debía pasar la reforma energética, fue propuesta la desaparición de los institutos electorales estatales, los cuales serían sustituidos por un Instituto Nacional Electoral que tendría la facultad de organizar todas las elecciones en el territorio mexicano.

Pese a que la propuesta inicial en la reforma política era la desaparición de los institutos electorales estatales, luego del consenso entre los grupos parlamentarios, la iniciativa sufrió varias modificaciones que aseguran su permanencia. Tanto el jefe de gobierno del Distrito Federal, como el gobernador del Estado de México, se pronunciaron a favor de la creación del Instituto Nacional Electoral (INE) pero rechazaron la desaparición de los institutos electorales estatales. Opinaron que la creación del INE es factible siempre y cuando se mantengan los institutos locales, encontrando una fórmula en la que el INE sea el que resuelva la elección de los consejeros electorales en las entidades del país. ${ }^{1}$

Como se detalla en la exposición de motivos de la reforma político electoral de 2014, para cumplir con el propósito fundamental de imparcialidad, transparencia, integridad, eficiencia y efectividad, vocación de

1 Maza, Zarife, "Mancera rechaza la desaparición del IEDF", Azteca Noticias, 28 octubre de 2013, en $h t t p: / / w w w . a z t e c a n o t i c i a s . c o m . m x /$ mexico/172371/mancera (consultada el 15 de abril de 2014). 
servicio y profesionalismo en los órganos electorales locales, no es pertinente su desaparición, sino establecer la homologación de algunos aspectos para el cumplimiento de este fin, como es el procedimiento de nombramiento de los consejeros electorales, su duración y el sistema de garantías para su cabal desempeño. ${ }^{2}$

Bajo ese razonamiento, a fin de fortalecer a las autoridades electorales de las entidades federativas, la reforma constitucional de 2014 en materia política electoral, ha retirado alguna de las funciones más controvertidas a los órganos locales que han puesto en duda su imparcialidad. De igual manera, con el propósito de garantizar las condiciones de legalidad, certidumbre, equidad y transparencia en los procesos electorales locales, se pone énfasis en las normas preventivas de la intromisión de otros poderes en la integración, las decisiones y el actuar de los órganos públicos locales electorales. Entre otros fines se busca homologar la calidad de los procesos electorales federal y estatal.

Al hacer un análisis de las ventajas y desventajas que implica la creación de un órgano nacional en la materia electoral, se concluye que la actuación de los órganos locales puede reforzarse a través de la intervención del INE. Ya superada la inquietud de desaparecer a los institutos electorales estatales, cobra significado la homologación de algunos aspectos que permitan cumplir el propósito fundamental de imparcialidad, independencia e integridad en este tipo de organismos, por ese motivo, se propone ampliar las atribuciones de carácter nacional del INE, para asumir algunas que hasta ahora realizan los organismos electorales locales. ${ }^{3}$

Una vez resuelto que en las entidades federativas las elecciones locales estarán a cargo de organismos públicos autónomos, se abordó el esquema de distribución de competencias. De esta forma, el artículo 41 constitucional, fracción $\mathrm{V}$, apartado $\mathrm{C}$, dispone que los organismos públicos locales ejercerán funciones en las siguientes materias:

- Derechos y el acceso a las prerrogativas de los candidatos y partidos políticos.

- Educación cívica.

2 Senado de la República. LXII Legislatura. "Exposición de motivos", Dictamen de las Comisiones Unidas de Puntos Constitucionales; de Gobernación; de Reforma del Estado, de Estudios Legislativos, en relación con las iniciativas con proyecto de decreto por el que se reforman y adicionan diversos artículos de la Constitución Política de los Estados Unidos Mexicanos en materia política-electoral, México, 2 de diciembre de 2013, p. 125.

3 Ibidem, p. 124. 
- Preparación de la jornada electoral.

- Impresión de documentos y la producción de materiales electorales.

- Escrutinios y cómputos en los términos que señale la ley.

- Declaración de validez y el otorgamiento de constancias en las elecciones locales.

- Cómputo de la elección del titular del Poder Ejecutivo.

- Resultados preliminares; encuestas o sondeos de opinión; observación electoral y conteos rápidos.

- Organización, desarrollo, cómputo y declaración de resultados en los mecanismos de participación ciudadana que prevea la legislación local.

- Todas las no reservadas al Instituto Nacional Electoral y las que determine la ley.

Sin embargo, a efecto de dotar de funcionalidad al sistema de competencias propuesto, se prevé que en los supuestos que contempla la Ley General de Instituciones y Procedimientos Electorales (LGIPE), con la aprobación de una mayoría de cuando menos ocho votos del Consejo General, el INE pueda asumir directamente la realización de actividades propias de la función electoral que corresponde a los órganos locales electorales y, cuando su trascendencia lo amerite, atraer a su conocimiento cualquier asunto de la competencia de los órganos locales. Por supuesto, no pasa por alto que es facultad exclusiva del INE designar y remover a los integrantes del órgano superior de dirección de los organismos públicos locales, tema al que se dedica el presente trabajo de investigación.

\section{El nombramiento de los consejeros electorales locales como facultad exclusiva del Instituto Nacional Electoral}

Conferida al INE la facultad para designar al consejero presidente y los consejeros electorales de los organismos públicos locales, su ejercicio ha suscitado distintos puntos de vista. Entre consultas dirigidas al propio Instituto Nacional Electoral o resoluciones emitidas por el Tribunal Electoral del Poder Judicial de la Federación (TEPJF), se ha explorado la permanencia de los consejeros electorales locales en su encargo, así como su designación por parte de los congresos estatales.

En un primer punto de vista, mediante sentencia del 10 de abril de 2014, la Sala Superior del TEPJF se pronunció sobre la permanencia de los con- 
sejeros electorales locales. A través de un juicio de revisión constitucional, el Partido Cruzada Ciudadana impugnó la determinación del Tribunal Electoral del Estado de Nuevo León, en la cual se confirmó la validez de un acuerdo emitido por el pleno de la Comisión Estatal del Estado de Nuevo León. Según el partido actor, como resultado de la reforma constitucional en materia político electoral publicada en el Diario Oficial de la Federación el 10 de febrero de 2014, han desaparecido los institutos electorales estatales debido a la creación de los organismos públicos locales, en ese sentido, dado que carecen de legitimación los actos que emitan con posterioridad a la entrada en vigor del decreto respectivo, el partido promovente afirma que el tribunal responsable en forma errónea considera que la Comisión Estatal del Estado de Nuevo León debe seguir actuando legalmente.

De acuerdo al planteamiento formulado por el partido actor, a efecto de dar certeza y seguridad jurídica a la actuación de las autoridades electorales locales actualmente en funciones, la Sala Superior del TEPJF procedió a realizar la interpretación constitucional de las disposiciones aplicables del decreto. En términos de la exposición de motivos, así como de la lectura integral del mismo decreto, se concluye que los órganos locales electorales en ningún momento desaparecen, únicamente sufren ajustes con los que se busca fortalecer su autonomía. Conforme la propia reforma constitucional, debe ser el Consejo General del INE quien designe a los consejeros de los nuevos organismos públicos locales electorales $y$, en tanto eso no suceda, seguirán en su encargo los integrantes de los organismos electorales que se encontraban en funciones a la fecha en que entró en vigor el decreto, con lo que se busca preservar el principio de certeza que debe imperar en la actuación de toda autoridad electoral. ${ }^{4}$

Resulta importante destacar que la reforma constitucional deposita la función sustancial de organizar las elecciones de todo el país en el INE, como la máxima autoridad administrativa en la materia, entre cuyas atribuciones se establece la facultad de designar a los integrantes de los órganos de dirección de los organismos públicos locales electorales. Ahora bien, como se dispone en el artículo quinto transitorio del Decreto antes referido, mientras no entren en vigor las leyes reglamentarias que el Congreso de la Unión debía expedir a más tardar el 30 de abril de 2014, el INE ejercerá las atribuciones que las leyes vigentes otorgan al Instituto Fede-

4 Tribunal Electoral del Poder Judicial de la Federación, Expediente SUP-JRC-10/2014,

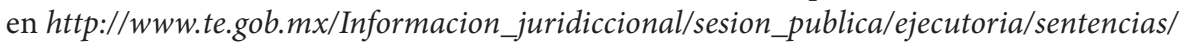
SUP-JRC-10-2014.pdf (consultada el 19 de abril de 2014), p. 22. 
ral Electoral (IFE). En ese sentido, a la fecha el INE no podía designar a los nuevos integrantes de ninguno de los organismos locales en materia electoral, pues no habían sido aprobadas las leyes secundarias a que se refiere el artículo segundo transitorio del Decreto que contiene la reforma constitucional. Por tal motivo, los institutos electorales locales siguen integrados por los mismos consejeros que se encontraban en funciones al 11 de febrero de 2014.

En consecuencia, dado que los argumentos hechos valer por el partido actor resultan infundados, toda vez que por mandato constitucional aún no se actualizan los supuestos para que el Consejo General del INE se encuentre en la posibilidad de designar a los nuevos consejeros electorales locales, así como tampoco se han expedido las leyes que regulen la actuación de los organismos públicos locales electorales, es imposible suponer que lo actuado por quienes se encuentran en funciones carece de efectos jurídicos, pues las actuales autoridades electorales continúan en su encargo, con las mismas atribuciones que les confiere la legislación vigente. ${ }^{5}$

Otro punto de vista a considerar es el que se contiene en el Acuerdo INE/CG07/2014, emitido por el Consejo General del INE al atender la consulta planteada por Alberto Alonso Criollo, en su carácter de consejero presidente del Instituto Estatal Electoral y de Participación Ciudadana de Oaxaca, en cuanto a que el Instituto Nacional Electoral emita un criterio orientador respecto a si él debe permanecer o no en su encargo, pues su nombramiento concluye el 8 de abril de 2014.

Apoyada la argumentación del INE en una consideración básica, se manifiesta que ya no serán los congresos locales ni los acuerdos políticos de los actores en los estados, ya sean reales o hipotéticas las intromisiones de los poderes locales, quienes definirán la integración de los organismos públicos locales. No cabe duda alguna que en cuanto esté vigente la legislación secundaria, el INE debe ejercer esa atribución y cumplir la responsabilidad de nombrar un consejero presidente y seis consejeros electorales en cada entidad federativa.

Como se razona en la parte considerativa del Acuerdo, el Poder Reformador de la Constitución previó una situación similar, toda vez que el INE aún no tiene atribuciones para nombrar a los consejeros electorales locales. No obstante, es una decisión expresa que esa atribución ya no queda establecida en las normas electorales estatales que siguen vigentes, pues se oponen a lo previsto en la Constitución. En términos del artículo

\footnotetext{
5 Ibidem, p. 25.
} 
noveno transitorio del Decreto, se establece una excepción respecto a la designación del consejero presidente y los consejeros electorales locales, ya que los "actuales consejeros", esto es, los consejeros que ocupaban ese cargo a la entrada en vigor de la reforma, continuarán en su encargo hasta en tanto se realicen las designaciones por el Consejo General del Instituto Nacional Electoral. ${ }^{6}$

A mayor abundamiento, si bien es clara la Constitución Política al conferir esa facultad al INE, en términos del artículo 116, fracción IV, párrafo 2o., también lo es que en el artículo noveno transitorio del citado decreto, se establece que los actuales consejeros continuarán en su encargo hasta en tanto se realicen las designaciones a que se refiere el propio precepto. Es decir, mientras el Instituto no pueda ejercer esa atribución por la ausencia de las leyes reglamentarias, los consejeros electorales locales seguirán en el desempeño de su encargo. ${ }^{7}$

Frente al uso prolífico que en los últimos años se ha hecho de los artículos transitorios constitucionales, diversos académicos e investigadores han señalado que, más allá de la discusión académica, los artículos transitorios son letra constitucional de plena vigencia y de clara jerarquía normativa, por tanto, la suerte de los consejeros electorales en funciones al 11 de febrero de 2014 está dicha no por los marcos normativos locales, sino por la Constitución general de la República.

Tal como lo expresa la Sala Superior del TEPJF, la supremacía constitucional consiste en que la regularidad constitucional está jerárquicamente por encima de cualquier autoridad o legislación secundaria. Así, de la relación entre fuerza vinculante y supremacía constitucional se genera la necesidad de que todas las autoridades se sometan a la ley fundamental. Si la Constitución obliga a la totalidad de sujetos y operadores jurídicos, incluso los privados, los juzgadores tienen un papel preponderante en la vigencia y defensa de la constitucionalidad, ello implica que deben interpretar todas y cada una de las partes del texto fundamental, incluyendo los artículos transitorios del decreto, previstos para darle funcionalidad a

6 Instituto Nacional Electoral. Acuerdo del Consejo General INE/CG07/2014 por el que se da respuesta a la consulta planteada por el C. Alberto Alonso Criollo, contenida en el oficio número IEEPCO/PCG/0468/2014, de fecha 6 de abril de 2014, recibido en la Secretaría Ejecutiva el 7 del mismo mes y año disponible en: http://www.ife.org.mx/ portal/site/ifev2 (consultada el 3 de mayo de 2014), p. 15.

7 Murayama Ciro, Instituto Nacional Electoral, Versión estenográfica de la Sesión Extraordinaria del Consejo General del Instituto Nacional Electoral, celebrada el 11 de abril de 2014, en el salón de sesiones del propio instituto, en http://www.ife.org.mx/portal/site/ ifev2 (consultada el 19 de abril de 2014), p. 76. 
la reforma constitucional ya que establecen diversas reglas y mecanismos con ese fin. ${ }^{8}$

Se suma como precedente otro juicio resuelto por la Sala Superior del TEPJF, relativo a declarar la incompetencia de un congreso local para designar a consejeros electorales estatales. En una sentencia emitida el 15 de abril de 2014, se resolvió que el Congreso del Estado de Tamaulipas carece de facultades para decidir la reelección o nombramiento de consejeros. Como se advierte en el fallo, la configuración y el sistema de designación de los consejeros de los organismos públicos locales ha cambiado, pues su designación corresponde ahora al Consejo General del Instituto Nacional Electoral en los términos previstos en la ley.

Cuando un Congreso local, de acuerdo con su normativa vigente, atiende el hecho de nombrar a consejeros electorales después del 11 de febrero de 2014, aun si en dicha norma está prevista esa facultad, el órgano legislativo deja de observar lo establecido en el decreto de reforma político electoral, en especial lo dispuesto en el artículo noveno transitorio. En este caso, la norma constitucional establece una temporalidad en la duración en el cargo de los consejeros electorales locales, toda vez que la regla dispone que permanecerán en el mismo hasta en tanto los designe el Consejo General del INE.

En otras palabras, como lo razona la Sala Superior del TEPJF, la nueva forma de integración de los organismos públicos locales electorales debe contrastarse con el método de elección de los consejeros estatales previo a la entrada en vigor del Decreto, esto es, al 11 de febrero de 2014, designación que entonces sí le correspondía a los congresos locales. A partir de entonces, existe una norma constitucional que prescribe una nueva modalidad en la designación de los consejeros electorales locales, reservando esa facultad al Consejo General del INE. En tal medida, ante la evidencia de que la designación haya sido hecha por autoridad incompetente, debe considerarse inválido el procedimiento de designación llevado a cabo por un Congreso local y revocarse por completo, pues dicho procedimiento quedó derogado implícitamente con la entrada en vigor de la reforma constitucional. ${ }^{9}$

Una premisa elemental en la designación de los consejeros electorales locales, es que resulta indebida si la realiza una autoridad o Congreso

8 Tribunal Electoral del Poder Judicial de la Federación, Expediente SUP-JRC-14/2014, disponible en: http://www.te.gob.mx/Informacion_juridiccional/sesion_publica/ejecutoria /sentencias/SUP-JRC-14-2014.pdf (consultada el 23 de abril de 2014), pp. 49 y 50.

9 Ibidem, p. 56. 
local. Al respecto el texto del artículo noveno transitorio del Decreto determina con claridad dos cuestiones fundamentales:

1) El Consejo General el INE designará a los nuevos consejeros de los organismos locales.

2) Los actuales consejeros continuarán en su encargo hasta el momento en que se realicen las designaciones pertinentes.

Al existir una norma constitucional que establece una nueva modalidad en la designación de consejeros electorales, previa a la designación que realice un Congreso local, como sucedió en el estado de Tamaulipas en marzo de 2014, la designación hecha por una autoridad estatal en esos términos violenta lo dispuesto en el régimen transitorio en el que se determina que los actuales consejeros continuarán en su cargo. De forma consecuente, para mantener la fuerza normativa de la Constitución o, de otro modo, su eficacia operativa, el intérprete debe privilegiar aquella opción que optimice el contenido de la norma fundamental, sin dejar de lado los artículos transitorios.

En virtud de la supremacía constitucional, aun cuando no se haya dispuesto de manera expresa, quedan implícitamente derogadas las normas locales que rigen la designación de consejeros electorales. Tomando en cuenta que el referido transitorio noveno del Decreto, establece debidamente, en cierta forma, el camino a seguir en el proceso de designación de los consejeros electorales locales, procede revocar el nombramiento que realicen los Congresos estatales, ya que la nueva conformación del sistema de designación de los consejeros electorales locales se ha visto modificada. En consecuencia debe respetarse la nueva configuración constitucional prevista por el legislador, en la cual la autoridad competente para designar a los consejeros electorales es diferente al Congreso local y en ella se estableció el régimen transitorio correspondiente para el periodo de vacatio legis.

Distinta solución a las anteriores fue prevista por el legislador en el Estado de México, ante la inminente reforma constitucional se introdujeron cambios en el código electoral de esa entidad. Según lo establece el artículo 89 de tal ordenamiento, reformado en noviembre de 2013, la legislatura designará a los consejeros electorales a más tardar el 30 de noviembre del año que corresponda, los consejeros designados entrarán en funciones el 1o. de enero del año siguiente al de su designación. Si cumplido el plazo señalado con anterioridad, no se hubieren aprobado las designaciones de quienes habrán de desempeñar el cargo para el pe- 
riodo siguiente, seguirán en vigor los nombramientos anteriores en tanto la Legislatura apruebe la designación de los nuevos. En ningún caso se entenderá esto como ratificación del encargo.

Frente a la reforma del artículo 116 constitucional, fracción IV, así como cuarto y noveno transitorios del decreto correspondiente, quedó excluido del ámbito de competencia de los congresos de las entidades federativas la facultad de realizar nombramientos de consejeros electorales de los organismos públicos locales, ya que ésta se trasladó al Instituto Nacional Electoral. Este nuevo esquema de designaciones a cargo del INE habrá de implementarse con antelación al inicio del siguiente proceso electoral posterior a la entrada en vigor de la reforma constitucional. De tal suerte queda tácitamente derogada una disposición como la anterior, pues daría lugar a la inaplicación de la norma.

Bajo esa línea argumentativa, la Sala Superior del TEPJF estima que las disposiciones de las entidades federativas que servían de base a un congreso local para efectuar esa clase de nombramientos quedaron implícitamente derogadas con la entrada en vigor del decreto de reforma constitucional. Esto es así porque el nuevo modelo de designaciones de los consejeros electorales de los organismos públicos locales entró en vigor el 11 de febrero de 2014, partir de entonces su designación es una facultad exclusiva que corresponde al INE, el cual ya se encuentra debidamente integrado y en funciones. ${ }^{10}$

\section{Importancia de los aspectos subjetivos en la designación de los consejeros electorales locales}

Como sucede a nivel nacional, los consejeros electorales locales forman parte de un selecto grupo de funcionarios públicos de primer nivel. La relevancia adquirida por este particular tipo de servidores se debe a distintas consideraciones. Su cargo obedece a una verdadera "función pública" que se desempeña a través de organismos públicos anteriormente denominados institutos electorales estatales. Integran el órgano central de mayor importancia y desempeñan un papel de primer orden dentro de la democracia estatal. Son funcionarios permanentes del Estado, cuya in-

10 Tribunal Electoral del Poder Judicial de la Federación, Expediente SUPJDC-333/2014, en: http://www.te.gob.mx/Informacion_juridiccional/sesion_publica/ejecu toria/sentencias/SUP-JDC-333-2014.pdf (consultada el 24 de abril de 2014), pp. 20 y 21. 
dependencia exige estabilidad, sin encontrarse sujetos a cambios políticos y exentos de subordinación con respecto a otra clase de autoridades. ${ }^{11}$

Uno de los elementos más significativos para consolidar la autoridad y la reputación de las instituciones electorales y, sin lugar a duda, una de las más sólidas garantías para el adecuado desarrollo de los procesos electorales en nuestro país, tanto a nivel federal como estatal, es la ciudadanización de los organismos encargados de organizar y vigilar el desarrollo de los comicios, aspecto sin el cual no hubiese sido posible transitar hacia la legitimidad electoral de la representación popular en todos los ámbitos.

En el contexto de ciudadanización de los organismos electorales, se ha requerido de manera progresiva la profesionalización en el desarrollo de sus funciones. La evolución de los perfiles exigidos para desempeñar el cargo se aproxima, más o menos, a los que son recomendables para los consejeros electorales a nivel nacional. Ya ha quedado superada aquella etapa de reclutamiento abiertamente partidista y hoy se apuesta más a la experiencia profesional y formación académica. Si la función electoral es una función altamente especializada y notoriamente próxima a la política, es indispensable que los consejeros electorales cuenten con el suficiente reconocimiento en la materia.

Modelo referente para llevar al ámbito de las legislaciones estatales ciertas pautas, el IFE también marcó la evolución en la tipología de los consejeros electorales en el contexto estatal. Si bien los consejeros ciudadanos representan una aportación inicialmente impulsada por la federación, fue consolidada por los estados apenas unos años después. Acorde a la necesidad de avanzar hacia la profesionalización de la función electoral, en 1996 se produjo un cambio relevante, para obtener un asiento en el colegio de consejeros se solicitaba contar con un perfil "especializado". Bajo los distintos argumentos que dieron lugar a los adjetivos utilizados, ciudadanos expertos en derecho electoral, este perfil condicionó también a los consejeros electorales de las entidades federativas. ${ }^{12}$

A fin de garantizar que los elementos humanos, cuya trayectoria y reconocimiento, así como su falta de militancia o vínculo con algún partido o gobierno, sigan siendo un valor fundamental y soporte a la vez de un mecanismo para fortalecer la imparcialidad y transparencia de los proce-

11 Astudillo, César y Córdova Vianello, Lorenzo, Los árbitros de las elecciones estatales: Una radiografía de su arquitectura institucional, México, Instituto Electoral y de Participación Ciudadana del Estado de Jalisco-UNAM, Instituto de Investigaciones Jurídicas, 2010, p. 111.

12 Ibidem, p. 116. 
sos electorales, a partir de la vinculación con la sociedad organizada, la elección o designación de los consejeros electorales ha cobrado notoria trascendencia, pues a través de un procedimiento objetivo y adecuado debe asegurarse, en lo posible, que esta clase de funcionarios tenga la independencia, los conocimientos, habilidades y sensibilidad que demanda la función electoral. ${ }^{13}$

Propio de la transición democrática mexicana, el factor "desconfianza" también ha permeado la elección y el desempeño de los consejeros electorales. Como lo demuestra la experiencia comparada, la figura del consejero electoral representa un producto muy nuestro que parece no tener un correlativo exacto en otros sistemas político electorales. Pieza clave en la función electoral, además de su perfil altamente técnico y especializado, el consejero recibe la encomienda de transmitir confianza social. Está comprometido a consolidar una institución que genere convicción en los ciudadanos de que el sufragio emitido será contado con pulcritud y certidumbre, de manera que los resultados electorales sean confiables. Su condición de árbitro imparcial, a menudo cuestionada, debe favorecer la construcción de un ánimo y cultura democrática, pues no parece suficiente organizar con éxito y pulcritud el proceso electoral.

Acorde con la ampliación de atribuciones de los organismos electorales, la tipología de los consejeros electorales ha venido evolucionando. Si el criterio de selección privilegiaba el seguimiento de las tareas operativas vinculadas con la capacitación, la organización y el desarrollo del proceso electoral, en la actualidad debe favorecer la inclusión de perfiles más completos que incluya cualidades de percepción política y resolutiva. Su cercanía con la política y el trato diario con los partidos, hace que los consejeros exhiban la cualidad de dialogar, consensar y acordar con los protagonistas de la competencia electoral. Además de reunir capacidades técnicas, los consejeros requieren la aptitud de entender cómo se integra el marco normativo y de qué manera se teje el entramado político, su perfil es ahora ambivalente, peculiaridad que lo proyecta como un funcionario sensiblemente distinto al resto de los servidores públicos. ${ }^{14}$

Más allá de los requisitos de elegibilidad que exige la legislación aplicable, por tratarse de un funcionario de relevancia significativa para el orden democrático, el aspirante a consejero debe estar familiarizado con

13 Instituto Electoral del Distrito Federal. Secretaría Ejecutiva. Dirección Ejecutiva del Servicio Profesional Electoral, Programa de Capacitación de Consejeros Electorales Distritales, México, 2009, p. 3.

14 Astudillo, César y Córdova Vianello, Lorenzo, op. cit., p. 121. 
las últimas corrientes y escuelas del pensamiento jurídico. Sin embargo, como no todas sus decisiones son de carácter jurídico, se requiere de conocimiento y experiencia en la conducción de instituciones nacionales. Lejos de ser un técnico en la organización de elecciones, el consejero debe ser portador de determinadas habilidades políticas y poseer la sensibilidad que facilite el diálogo y la negociación, a fin de construir los acuerdos necesarios en la conducción de la contienda electoral.

Ahora bien, el consejero no necesita ser un funcionario "químicamente puro", pues es pertinente que esté profundamente familiarizado con los valores democráticos constitucionales. Una cosa es la imparcialidad y otra, muy distinta, la exigencia de neutralidad que, en su calidad de "posición avalorativa", es incompatible con nuestro sistema democrático. De tal suerte, el consejero particularmente técnico o impecablemente aséptico constituye más un ideal inalcanzable que una realidad efectiva. La forma como se aproxima, interpreta y decide las cuestiones que se someten a su aprobación, se encuentra condicionada por un conjunto de elementos que ponen a prueba la objetividad como principio rector de la función electoral. En este sentido, su actuación adquiere distintos matices de conformidad con la ideología que presenta y que le representa. Como otros funcionarios de alto nivel, en la forma de concebir la realidad, el consejero no ésta exento de resentir la influencia de valores, principios o ideales. Por lo mismo, es difícil sostener que los consejeros se muestren plenamente objetivos y destacadamente neutrales. Sus decisiones llevan consigo una leve porción de subjetividad que no puede negarse. ${ }^{15}$

Además de los atributos hacia el exterior, el perfil idóneo del consejero requiere aptitudes que puedan desplegarse dentro de un órgano colegiado y plural. Dado que en los consejos generales se produce de manera invariable una convivencia entre pares y existe el imperativo de analizar temas y aprobar acuerdos desde la pluralidad de visiones, es importante que el consejero tenga la cualidad para fijar con precisión su posicionamiento y argumentar de forma coherente, consistente y persuasiva. Por supuesto, es conveniente saber escuchar la postura de terceros y la habilidad de propiciar y participar en el diálogo. Intervenir en la sesión de un consejo general implica apartarse con cierta regularidad de posiciones inamovibles, pues una armónica composición de posturas individuales deriva con mayor frecuencia en consensos y acuerdos. ${ }^{16}$

15 Ibidem, p. 124.

16 En los Lineamientos del Instituto Nacional Electoral para la Designación de Consejeros Presidentes y Consejeros Electorales de los Organismos Públicos Locales, apro- 


\section{Procedimiento de elección de los consejeros de los organismos públicos locales electorales}

De conformidad con la normativa constitucional y legal, la elección de los consejeros electorales es un acto complejo, reglado en cuanto al procedimiento y discrecional en lo relativo a la elección de los ciudadanos que ocuparán el cargo. Al establecer un procedimiento, el legislador procura sentar las bases para emitir una convocatoria dirigida a los ciudadanos residentes en cada entidad federativa, a través de la cual se dé publicidad al plazo de inscripción, el procedimiento a seguir para la elección de los candidatos, su posterior designación, las reglas y métodos para verificar el cumplimiento de los requisitos, casi siempre, con la intención de una valoración objetiva e imparcial de los aspirantes. ${ }^{17}$ Sin embargo, sujetar a un procedimiento al órgano o autoridad, facultado para llevar a cabo la elección, no implica acotar su facultad discrecional para designar a quienes habrán de ocupar el cargo. En ello estriba precisamente el reto de realizar una acertada elección.

Según lo establece el artículo 101 de la recién aprobada y promulgada Ley General de Instituciones y Procedimientos Electorales (LGIPE), para la elección del consejero presidente y los consejeros electorales de los organismos públicos locales, el INE deberá observar el siguiente procedimiento:

a) El Consejo General emitirá convocatoria pública para cada entidad federativa que corresponda, en la que deberán considerar expresamente los cargos y periodos a designar, plazos del proceso de designación, órganos ante quienes se deberán inscribir los interesados, requisitos, documentación y el procedimiento a seguir;

b) La Comisión de Vinculación con los Organismos Públicos Locales tendrá a su cargo el desarrollo, vigilancia y la conducción del proceso de designación;

c) La inscripción y entrega de documentos para el proceso de designación se hará en cada entidad federativa o ante la Secretaría del Consejo General.

bados en sesión extraordinaria del Consejo General, celebrada el 6 de junio de 2014, se hace mención de la idoneidad y capacidad del perfil de los aspirantes a consejeros electorales. En la medida de lo posible, se procurará atender la equidad de género y una composición multidisciplinaria mediante la evaluación objetiva e imparcial de los aspirantes.

17 Solorio Almazán, Héctor, Partidos políticos y órganos legislativos. Casos sobre designación de consejeros y magistrados electorales, México, Tribunal Electoral del Poder Judicial de la Federación, 2009, p. 20. 
Para la difusión del proceso y recepción de documentación de los aspirantes, la Comisión se auxiliará de los órganos desconcentrados del Instituto en las treinta y dos entidades federativas;

d) La Comisión deberá integrar una lista de hasta cinco nombres de candidatos por cada vacante en la entidad federativa, para ocupar los cargos de Consejeros Electorales de los Organismos Públicos Locales.

Para tal efecto, la Comisión deberá desarrollar los mecanismos de evaluación sobre la idoneidad y capacidad del perfil.

La Comisión podrá allegarse de información complementaria para el desarrollo del proceso de designación de las propuestas de integración de cada uno de los consejos locales de los Organismos Públicos Locales.

En todos los casos, los nombres contenidos en las propuestas deberán cumplir con los requisitos que establecen la Constitución y esta Ley;

e) La Comisión presentará al Consejo General una lista de hasta cinco nombres por vacante en la entidad federativa.

Cuando en el mismo proceso de selección se pretenda cubrir más de una vacante, la Comisión presentará al Consejo General una sola lista con los nombres de la totalidad de los candidatos a ocupar todas las vacantes.

Las listas que contengan las propuestas deberán ser comunicadas al Consejo General con una anticipación no menor a setenta y dos horas previas a la sesión que corresponda;

f) El Consejo General designará por mayoría de ocho votos al Consejero Presidente y a los Consejeros Electorales de los Organismos Públicos Locales, especificando el periodo para el que son designados, y

g) El Consejo General deberá publicar en el Diario Oficial de la Federación y el equivalente en la entidad federativa, así como comunicar a las autoridades locales dicha designación.

Como todo procedimiento, se encuentra en sí mismo dirigido a la autoridad y no a los ciudadanos interesados. De trascendencia sustantiva, se integra de diversas etapas concatenadas entre sí. De tal forma, solo cuando esa cadena de actos sucesivos se realiza de manera correcta puede estimarse que el procedimiento es válido.

Bajo la firme decisión de centralizar la competencia y atribución conferida al INE, no participa en el procedimiento ningún órgano ajeno al Instituto. El sistema de designación de los consejeros locales pretende blindarse respecto de toda injerencia externa, ya sea de gobernadores o de dirigencias nacionales y estatales de los partidos políticos. Con base en el principio de autonomía, se trata de un procedimiento estrecho y cerrado que excluye la convergencia de un elevado número de voluntades 
políticas, pues niega la implicación directa de prácticamente todos los actores políticos y sociales. ${ }^{18}$

Para perfeccionar la designación de los consejeros electorales locales, el sistema de nombramiento tiene la misión de ordenar cada una de las etapas, actos y pasos concretos en el mismo. Sin especificar el papel que desempeñan los aspirantes dentro de la dinámica del procedimiento, no se alude al nivel de interacción que puedan tener con otros sujetos. La novedad es incorporar la participación de una Comisión de Vinculación con los Organismos Públicos Locales, conformada por cuatro consejeros electorales designados por una mayoría de cuando menos ocho votos del Consejo General del INE. Esta Comisión permanente, con presidencia rotatoria anual entre sus integrantes, es la encargada del desarrollo, vigilancia y la conducción del proceso de designación.

Es común en el procedimiento emplear términos como elegir, designar o nombrar. En estricto sentido, los consejeros no emanan de un proceso de elección, sino de un método de designación. Precisamente, se trata de un acto complejo que se integra por distintas etapas las cuales, para que sea armónico, cuentan con un lugar definido y predeterminado. Suele ocurrir que esta clase de procedimiento se compone de cuatro etapas: identificación de los aspirantes al cargo, selección de los candidatos, designación y nombramiento formal. ${ }^{19}$

Etapa sustantiva es la selección de candidatos, cuya finalidad es seleccionar dentro del universo de aspirantes a las personas que serán formalmente nominadas para acceder al cargo, la facultad está ahora conferida a la Comisión de Vinculación. Al respecto, se ha instrumentado un análisis individualizado de los aspirantes, en el que deberán desarrollarse los mecanismos de evaluación sobre la idoneidad y capacidad de perfil de cada candidato. Fase cronológicamente sucesiva, la etapa de designación confiere al Consejo General del INE la facultad discrecional de nombrar a los ciudadanos que ocuparán el cargo. Siempre es probable no optar por alguno de los propuestos.

18 Dispuesto en el Acuerdo del Consejo General del Instituto Nacional Electoral por el que se aprueba el Modelo de Convocatoria para la Designación de Consejeros Presidentes y Consejeros Electorales de los Organismos Públicos Locales, aprobado en la sesión extraordinaria celebrada el 20 de junio de 2014, con el apoyo de grupos de trabajo, académicos y técnicos, serán evaluados los aspirantes mediante examen de conocimientos, ensayo presencial, valoración curricular y entrevista. En la valoración de los currículos se considerarán aspectos como: historia profesional y laboral; apego a los principios rectores de la función electoral; aptitudes e idoneidad para el desempeño del cargo; participación en actividades cívicas y sociales; experiencia en materia electoral.

19 Astudillo, César y Córdova Vianello, Lorenzo, op. cit., p. 156. 
Acorde al mayor o menor número de requisitos de elegibilidad, el conjunto de personas que cumplen con el perfil para ser consejeros electorales puede ser amplio o restringido. Limitar ese número implica que en el procedimiento de designación se impongan filtros adicionales para que avancen solo quienes cumplan con los requerimientos. En el artículo 100 de la LGIPE, se establecen como requisitos de elegibilidad para ser consejero electoral local los siguientes:

a) Ser Ciudadano mexicano por nacimiento, que no adquiera otra nacionalidad, además de estar en pleno goce de sus derechos civiles y políticos;

b) Estar inscrito en el Registro Federal de Electores y contar con credencial para votar vigente;

c) Tener más de 30 años de edad al día de la designación;

d) Poseer al día de la designación, con antigüedad mínima de cinco años, título profesional de nivel licenciatura;

e) Gozar de buena reputación y no haber sido condenado por delito alguno, salvo que hubiese sido de carácter no intencional o imprudencial;

f) Ser originario de la entidad federativa correspondiente o contar con una residencia efectiva de por lo menos cinco años anteriores a su designación, salvo el caso de ausencia por servicio público, educativo o de investigación por un tiempo menor de seis meses;

g) No haber sido registrado como candidato ni haber desempeñado cargo alguno de elección popular en los cuatro años anteriores a la designación;

h) No desempeñar ni haber desempeñado cargo de dirección nacional, estatal o municipal en algún partido político en los cuatro años anteriores a la designación;

i) No estar inhabilitado para ejercer cargos públicos en cualquier institución pública federal o local;

j) No haberse desempeñado durante los cuatro años previos a la designación como titular de secretaría o dependencia del gabinete legal o ampliado tanto del gobierno de la federación o como de las entidades federativas, ni subsecretario u oficial mayor en la administración pública de cualquier nivel de gobierno. No ser jefe de gobierno del Distrito Federal, ni gobernador, ni secretario de gobierno o su equivalente a nivel local. No ser presidente municipal, Síndico o Regidor o titular de dependencia de los ayuntamientos, y

k) No ser ni haber sido miembro del servicio profesional electoral nacional durante el último proceso electoral en la entidad.

Tal y como ocurría anteriormente, el legislador determinó establecer de manera limitativa los cargos públicos que resultan incompatibles con la 
designación como consejero electoral local. Por esa razón, no es factible extender la restricción a las personas que desempeñan alguna función dentro de la administración pública.

Cuando el poder de designación estaba en manos de los congresos estatales, la facultad de identificar a los candidatos quedaba en los propios órganos representativos, a través de los grupos o fracciones parlamentarias. Abierto el método de selección, la facultad conferida al Consejo General del INE de emitir una convocatoria pública constituye un llamamiento para que todas aquellas personas interesadas concurran al proceso de designación. Dado que no está prevista la intervención de un comité técnico de expertos o una modalidad que haga menos amplio el espectro de los aspirantes, corresponde a la Comisión de Vinculación allegarse de información complementaria para integrar la lista de candidatos por cada vacante.

Toca a la Comisión de Vinculación analizar los requisitos de elegibilidad y dictaminarlos. Prevista la nominación colectiva, complementaria de la nominación por quintetas, el formato puede generar una auténtica competencia de méritos entre los aspirantes, fortaleciendo el nivel de legitimidad de quien resulta designado. Es importante destacar que la atribución de nominar a los candidatos confiere una amplia libertad a la Comisión de Vinculación para confeccionar el documento que, con las propuestas, será puesto a consideración del Consejo General del Instituto. En función de la modalidad adoptada para la presentación de las candidaturas, la lista resulta lo suficientemente amplia para dar capacidad de maniobra y decisión al Consejo General del INE.

Facultad discrecional del Consejo General, por mayoría de ocho votos, designará al consejero presidente y a los consejeros electorales de los organismos públicos locales, especificando el periodo para el que son designados. En caso de ocurrir una vacante, el Consejo General del INE hará la designación correspondiente de acuerdo al procedimiento previsto en la ley. Si la vacante se verifica durante los primeros cuatro años del encargo se designará un sustituto para concluir el periodo. Si la falta ocurre dentro de los últimos tres años, se designará un consejero para un nuevo periodo.

Derivado del proceso de designación, el Consejo General del INE puede decidir no integrar el número total de vacantes, en ese caso, deberá iniciarse un nuevo procedimiento respecto de las vacantes no cubiertas. Como se describe con detalle en el inciso posterior, cumplir con los requisitos de elegibilidad no significa necesariamente contar con el perfil idóneo para desempeñar el cargo. Reunir el perfil adecuado emana más de condiciones subjetivas que de consideraciones objetivas, por ese mo- 
tivo, tanto la Comisión de Vinculación como el Consejo General del Instituto deben echar mano de herramientas dirigidas a descubrir el plus que se requiere para ocupar el cargo de consejero presidente y consejero electoral de un organismo público local.

Sin estar previsto en el texto constitucional, el artículo décimo transitorio de la LGIPE incorpora que el Consejo General del Instituto deberá realizar los nombramientos de forma escalonada. Tres consejeros durarán en su encargo tres años; tres consejeros por seis años y un consejero por siete años. Desde luego se trata solo de la primera integración de un Consejo General de los organismos públicos locales electorales. Es importante señalar que en el precepto transitorio no se precisa la duración en el cargo del consejero presidente, es decir, no está claro si será designado por tres, seis o siete años. De acuerdo con la misma disposición transitoria, para los procesos electorales locales cuya jornada electoral se realice en 2015, el INE debe concluir el proceso de designación a más tardar el 30 de septiembre de 2014. Respecto de las otras entidades federativas la designación se realizará con antelación al inicio de su siguiente proceso electoral.

Es posible equivocarse con la designación de un consejero electoral local o que en el desempeño del cargo éste se aparte de los principios rectores de todo proceso electoral. Por esa razón, los consejeros electorales de los organismos públicos locales podrán ser removidos por el Consejo General del INE, si incurren en alguna de las causas graves previstas en el artículo 102 de la LGIPE:

a) Realizar conductas que atenten contra la independencia de la función electoral, o cualquier acción que genere o implique subordinación respecto de terceros;

b) Tener notoria negligencia, ineptitud o descuido en el desempeño de las funciones o labores que deban realizar;

c) Conocer de algún asunto o participar en algún acto para el cual se encuentren impedidos;

d) Realizar nombramientos, promociones o ratificaciones infringiendo las disposiciones generales correspondientes;

e) Emitir opinión pública que implique prejuzgar sobre un asunto de su conocimiento y no haberse excusado del mismo;

f) Dejar de desempeñar injustificadamente las funciones o las labores que tenga a su cargo, $y$

g) Violar de manera grave o reiterada las reglas, lineamientos, criterios y formatos que emita el Instituto en términos de la Base V, Apartado B), inciso 
a), numeral 5 de la Constitución. Para los efectos de este inciso se considera violación grave, aquélla que dañe los principios rectores de la elección de que se trate.

Decisión de enorme significado requiere de una mayoría calificada de ocho votos del Consejo General, quien debe notificar la resolución y proceder a ejecutarla. La remoción podrá aplicarse sin perjuicio de otra sanción que resulte procedente en términos de la legislación aplicable.

A grandes rasgos, el procedimiento de remoción es el siguiente. Cuando el secretario ejecutivo del Instituto tenga conocimiento de hechos que actualicen alguna de las causas graves previstas en la ley y considere que existen elementos de prueba, notificará personalmente al consejero electoral local de que se trate a través de la Unidad Técnica de lo Contencioso Electoral. En la notificación se expresará el lugar, día y hora en que tendrá verificativo la audiencia de ley. También los actos u omisiones que se le imputen, las consecuencias posibles y el derecho de comparecer asistido de un defensor. Concluida la audiencia, se concederá al consejero electoral un plazo de diez días para que ofrezca los elementos de prueba que estime pertinentes y que tengan relación con los hechos que se le atribuyen. Una vez desahogadas las pruebas admitidas, el secretario ejecutivo, dentro de los veinte días siguientes, someterá el dictamen con proyecto de resolución al Consejo General.

\section{Los retos del Instituto Nacional Electoral en la designación de los consejeros electorales locales}

Nada fácil es la responsabilidad del INE de llevar a cabo la designación de los consejeros de los organismos públicos locales. El ejercicio de esta atribución conlleva el desafío de realizar una designación que contribuya a restablecer y fortalecer la confianza en ese tipo de autoridades. Irradiar certeza a los partidos y candidatos de que las elecciones locales pueden llevarse a buen término, como garantía para un voto libre y una competencia limpia y equitativa. En justo contraste con el pasado inmediato que se trata de una autoridad sin injerencias y con atribuciones muy precisas y puntuales.

Un primer reto del INE es despolitizar la designación de los consejeros electorales locales y evitar todo intento injerencista. La búsqueda y designación de consejeros independientes, imparciales, confiables y objetivos, 
pero no necesariamente neutrales o avalorativos, compromete a seleccionar mejores fórmulas y perfiles de elección. Con el propósito de asegurar que al interior del órgano central de dirección no se dará un desequilibrio, sesgo o inclinación por un partido o fuerza determinada, la designación de los consejeros debe mantenerse alejada de intereses políticos.

Sin estar exento de presiones, deberá el INE lidiar con las inquietudes y ambiciones de partidos políticos, gobernadores y otras fuerzas del orden local. Si es verdad que esta clase de actores tenían metida la mano en la designación de los consejeros electorales estatales, es difícil suponer que sean capaces de contener esas ansias injerencistas. El pasado los condena y se trata de actores que no aceptan con buena actitud ser desplazados de su zona de influencia o confort.

Por corresponderle al INE y no a los congresos locales, la designación de los consejeros estatales puede llevar en principio una importante dosis de legitimidad. Este aspecto contribuye a mantener la exigencia de confiabilidad que se espera de los organismos públicos locales, quienes no deben permanecer como una institución de confianza media. A grandes rasgos son organismos que no pueden permitirse el lujo de administrar solo los procesos electorales, pues se trata de instituciones responsables de tutelar los principios democráticos y los derechos políticos plasmados en la Constitución. Más allá de asegurar la limpieza de los comicios, tienen la responsabilidad de defender el espacio público y consolidar el régimen democrático en el país. Por esas razones, al decidir su integración debe evitarse poner en duda su imparcialidad y apego a la ley. Privilegiar la confianza y legitimidad social de esta clase de autoridades exige una elección apartidista de los consejeros electorales locales.

Acorde al perfil ambivalente de esta clase de funcionarios, ya no es suficiente exhibir un alto grado de especialización en la materia. Como intermediarios efectivos entre la sociedad y el Estado, los consejeros electorales deben tener la percepción y sensibilidad política que les permita decidir de manera correcta sobre la nueva gama de asuntos que se les presenta. Si anteriormente el perfil exigía contar con una experiencia cuasi-jurisdiccional, en la actualidad es conveniente poseer la habilidad de realizar una adecuada lectura política de los temas. El hecho de mantenerse alejado de los intereses políticos, no conlleva a ser indiferente de las circunstancias y coyuntura política que rodea a la contienda electoral. ${ }^{20}$

Maximizar los consensos y buscar el mayor acuerdo posible al interior de los órganos centrales de decisión, demanda de los consejeros electo-

$20 \quad$ Ibidem, p. 121. 
rales capacidad de diálogo y negociación. No es suficientemente correcto asegurar la toma de decisiones solo por mayoría. Decidir al interior de un consejo general reclama tener la capacidad de superar las diferencias o desavenencias entre sus integrantes. Por encima de la apreciación personal se coloca la percepción colectiva, por supuesto, cuando parte de una interpretación correcta. De tal suerte, si los consejeros no obedecen a intereses políticos o compromisos partidarios, la posibilidad de superar sus diferencias es mayor.

Cualidad de carácter subjetivo, el INE debe revisar con extremo cuidado el perfil de los aspirantes y colocar en un plano sustantivo la experiencia en la toma de decisiones. La credibilidad y confianza en los organismos públicos locales estará determinada, en gran medida, por la categoría y prestigio de los consejeros, pero sobre todo por la capacidad para ponerse de acuerdo. Un consejo general en extremo dividido o atomizado manda señales equívocas a los actores políticos.

Otro aspecto a considerar es el relativo a homologar o estandarizar la calidad en la integración de los consejos generales, sin necesidad de recurrir a planteamientos diferenciados o de regionalización. Acorde con la reforma constitucional, artículo 116, fracción IV, los organismos públicos locales electorales contarán con un órgano de dirección superior que se integrará de la misma forma, un consejero presidente y seis consejeros estatales. Si en la disposición constitucional se decide uniformar la integración de los consejos generales y, en esencia, los organismos públicos comparten el mismo tipo y cúmulo de facultades, es sensato suponer que la calidad de sus integrantes puede ser homologada.

Todo aspirante a ocupar un cargo, ya sea público o de representación, debe satisfacer los requisitos de elegibilidad previstos en la norma. Referida a cuestiones inherentes a la persona, la elegibilidad supone reunir las cualidades que se estiman pertinentes en cada caso, significa que las condiciones individuales del aspirante corresponden a las exigidas por el legislador. A través de la elegibilidad se trata de asegurar la idoneidad en el desempeño del cargo e impedir la incompatibilidad entre diversas funciones. No se advierte en la ley que exista distinto nivel de exigencia para los aspirantes a consejeros electorales, en todos los casos, sin importar la entidad federativa, se exigen las mismas cualidades y condiciones. En ese sentido, mediante la selección y designación adecuada de los consejeros locales, el INE debe procurar homologar y aproximar, en lo posible, el nivel de desempeño de los consejeros.

Elegir a los capaces y no a los afines permite que el desempeño de los consejeros se acerque a su rendimiento óptimo. Si ocurre de esa forma se 
aleja la posibilidad de atraer una elección local, al menos por las causas que podrían imputarse a la falta de aptitud de los consejeros locales. De ahí la importancia de no dispensar o flexibilizar el cumplimiento de los requisitos exigidos en la ley. Evaluar de manera objetiva la formación académica, el desempeño profesional y las cualidades personales de los aspirantes, es un punto de partida irrebatible para el INE.

Asegurar la correcta conducción del proceso y hacer inviable o remota la atracción de la elección local, supone que el INE no lleve a cabo una designación equivocada o incorrecta de los consejeros estatales. Es cierto que es reglado el procedimiento de designación, por esa condición debe transcurrir como lo dispone la Constitución y la ley, no obstante, en el ámbito de la designación ésta es propiamente discrecional. En consecuencia, el poder de decisión que tiene en sus manos el Consejo General del INE constituye una atribución exclusiva y excluyente, ejecutada mediante el voto mayoritario de los consejeros generales del Instituto. Dentro del Consejo General del INE puede votarse por cualquiera de las personas que cumplan los requisitos de elegibilidad y que hayan sido nominados formalmente una vez transcurridas todas las fases del procedimiento. Al ejercer esa facultad discrecional, una vez fundada $y$ motivada la decisión del órgano central del Instituto, la ley permite a los consejeros del INE votar a favor de quien estimen conveniente, sin estar obligados a expresar los motivos que mueven su voluntad de elegir o no a determinada persona.

Acorde con lo anterior, dentro del universo de aspirantes al cargo, es probable una designación inadecuada, sobre todo cuando el cumplimiento de la responsabilidad descrita debe ajustarse a un plazo cierto y determinado, circunstancia que podría apresurar al INE a desahogar el procedimiento respectivo. Si en el terreno legislativo la prórroga es una opción cuestionada pero viable, no parece sensata en la elección de los consejeros locales. Vaya reto para el Instituto Nacional Electoral, designar a los consejeros idóneos y en un lapso breve de tiempo. El desafío pone al INE al filo de la navaja, la legitimación o no en la integración de los organismos públicos locales, así como su desempeño adecuado o no, podrían imputarse al Instituto.

Un aspecto final que no debe pasar inadvertido, es que el INE también es responsable de la integración completa del órgano de decisión en los organismos públicos locales. Muy criticada ha sido la Cámara de Diputados y algunas veces un congreso local, por demorar y propiciar la integración incompleta del IFE y de institutos electorales estatales. Tema de una sentencia emitida por la Sala Superior del Tribunal Electoral del 
Poder Judicial de la Federación, se destacó que en plena libertad de sus atribuciones constitucionales y legales, la Cámara de Diputados debió llevar a cabo todos los actos tendentes del procedimiento de designación de los consejeros electorales del entonces IFE, o bien, mediante un procedimiento diverso, ajustado a derecho, debía proceder a hacer la designación de los consejeros que corresponda. ${ }^{21}$ Con este precedente, el INE no tiene justificación constitucional o legal para mantener indebidamente integrado al Consejo General de un organismo público local.

\section{Consideraciones finales}

Primera. Real o hipotética la injerencia o intromisión de los gobernadores o los poderes estatales, la designación de los consejeros de los organismos públicos locales electorales es una atribución exclusiva y excluyente del INE. De tal suerte, ya fue excluida del ámbito de competencia de los congresos de las entidades federativas.

Segunda. Nada sencilla es la responsabilidad del INE de designar a los consejeros de los organismos públicos locales electorales. El ejercicio de esa atribución implica el desafío de realizar una designación que contribuya a restablecer y fortalecer la confianza en ese tipo de autoridades. Irradiar certeza a los partidos y candidatos de que las elecciones locales pueden llevarse a buen término, como garantía para un voto libre y una competencia limpia y equitativa. El desafío pone al Instituto al filo de la navaja, ya que podría imputársele la legitimación o no de los organismos públicos locales, así como su desempeño adecuado.

Tercera. Cualidad de carácter subjetivo, el INE debe revisar con sumo cuidado el perfil de los aspirantes y colocar en un plano sustantivo la experiencia en la toma de decisiones. Tanto la credibilidad como la confianza en los organismos públicos locales estarán determinadas, en gran medida, por la categoría y prestigio de los consejeros, pero sobre todo por la capacidad para ponerse de acuerdo. Un consejo general en extremo dividido o atomizado manda señales equívocas a los actores políticos.

Cuarta. Elegir a los capaces y no a los afines permite que el desempeño de los consejeros se acerque a su rendimiento óptimo. Si ocurre de

21 Sala Superior, Designación de Consejeros del Instituto Federal Electoral, Expediente SUP-JDC-12639/2011, Diálogos Judiciales, versiones estenográficas, México, núm. 2, Tribunal Electoral del Poder Judicial de la Federación, 2013, p. 132. 
esa forma se aleja la posibilidad de atraer una elección local, al menos por las causas que podrían imputarse a la falta de aptitud de los consejeros locales. El INE no debe dispensar o flexibilizar el cumplimiento de los requisitos exigidos en la ley. La formación académica, el desempeño profesional y las cualidades personales de los aspirantes deben valorarse objetivamente por el Instituto Nacional Electoral.

Quinta. Todo consejero electoral, sea nacional o local, no necesita ser un funcionario "químicamente puro", es pertinente que esté familiarizado con los valores democráticos constitucionales. Una cosa es la imparcialidad y otra, muy distinta, la exigencia de neutralidad que, en su calidad de "posición avalorativa", es incompatible con nuestro sistema democrático. El consejero particularmente técnico o aséptico constituye más un ideal inalcanzable que una realidad efectiva.

\section{Bibliografía}

Astudillo, César y Córdova Vianello, Lorenzo, Los árbitros de las elecciones estatales: una radiografía de su arquitectura institucional, México, Instituto Electoral y de Participación Ciudadana del Estado de Jalisco-UNAM, Instituto de Investigaciones Jurídicas, 2010.

Sala Superior, "Designación de consejeros electorales del Instituto Federal Electoral, Expediente SUP-JDC-12639/2011”, Diálogos Judiciales, México, núm. 2, Tribunal Electoral del Poder Judicial de la Federación, 2013.

Secretaría Ejecutiva, Dirección Ejecutiva del Servicio Profesional Electoral, Programa de Capacitación de Consejeros Electorales Distritales, México, Instituto Electoral del Distrito Federal, 2009.

Solorio Almazán, Héctor, Partidos políticos y órganos legislativos. Casos sobre designación de consejeros y magistrados electorales, México, Tribunal Electoral del Poder Judicial de la Federación, 2009.

\section{Hemerografía}

MAZA, Zarife, "Mancera rechaza la desaparición del IEDF”, Azteca Noticias, 28 octubre de 2013, en http://www.aztecanoticias.com.mx/mexi co/172371/mancera. 


\section{Documentos oficiales}

Instituto Nacional Electoral. Acuerdo del Consejo General INE/ CG07/2014 por el que se da respuesta a la consulta planteada por el C. Alberto Alonso Criollo, contenida en el oficio número IEEPCO/ PCG/0468/2014, del 6 de abril de 2014, recibido en la Secretaría Ejecutiva el 7 del mismo mes y año, en $h t t p: / / w w w . i f e . o r g . m x / p o r t a l / s i t e /$ ifev2.

Instituto Nacional Electoral. Acuerdo del Consejo General INE/ CG44/2014 por el que se aprueban los Lineamientos del Instituto Nacional Electoral para la Designación de Consejeros Presidentes y Consejeros Electorales de los Organismos Públicos Locales, aprobados en sesión extraordinaria del Consejo General, del 6 de junio de 2014, en $h t t p: / / w w w$.ife.org. $m x /$ portal/site/ifev2.

Instituto Nacional Electoral. Acuerdo del Consejo General INE/ CG69/2014 por el que se aprueba el Modelo de Convocatoria para la Designación de Consejeros Presidentes y Consejeros Electorales de los Organismos Públicos Locales, aprobados en sesión extraordinaria del Consejo General, del 20 de junio de 2014, en http://www.ife.org.mx/ portal/site/ifev2.

Murayama, Ciro, Instituto Nacional Electoral, Versión estenográfica de la Sesión Extraordinaria del Consejo General del Instituto Nacional Electoral, celebrada el 11 de abril de 2014, en el salón de sesiones del propio instituto, en http://www.ife.org. $m x /$ portal/site/ifev2.

Senado de la República. LXII Legislatura. "Exposición de motivos" en el Dictamen de las Comisiones Unidas de Puntos Constitucionales; de Gobernación; de Reforma del Estado, de Estudios Legislativos, en relación con las iniciativas con proyecto de decreto por el que se reforman y adicionan diversos artículos de la Constitución Política de los Estados Unidos Mexicanos en materia política-electoral, México, 2 de diciembre de 2013.

Tribunal Electoral del Poder Judicial de la Federación, Expediente SUPJRC-10/2014, en http://www.te.gob.mx/Informacion_juridiccional/se sion_publica/ejecutoria/sentencias/SUP-JRC-10-2014.pdf.

Tribunal Electoral del Poder Judicial de la Federación, Expediente SUPJRC-14/2014, en http://www.te.gob.mx/Informacion_juridiccional/se sion_publica/ejecutoria/sentencias/SUP-JRC-14-2014.pdf.

Tribunal Electoral del Poder Judicial de la Federación, Expediente SUPJDC-333/2014, en http://www.te.gob.mx/Informacion_juridiccional/ sesion_publica/ejecutoria/sentencias/SUP-JDC-333-2014.pdf. 